\title{
An Empirical Analysis of the Validity of Wagner's Law in China A Case Study Based on Gibbs Sampler
}

\author{
Yan Zheng \\ School of Economics, Huazhong University of Science and Technology \\ Hubei 430074, China \\ Finance and Economics College of Inner Mongolia \\ Huhehot 010051, China \\ E-mail:1cq@imut.edu.cn \\ Jiabai Li \\ St. Olaf College, 1500 St.Olaf Avenue Northfield, MN 55057, USA \\ E-mail: li@Stolaf.edu \\ Xiao-Li Wang \\ Management School of Inner Mongolia University of Technology \\ Inner Mongolia 010051, China \\ Management School of Purdue University Calumet \\ Hammond 46323, USA \\ E-mail: wangxiaoli586@126.com \\ Changqing Li \\ Management School of Inner Mongolia University of Technology \\ Inner Mongolia 010051, China \\ E-mail: glxy@imut.edu.cn
}

This paper was supported by the National Natural Science Foundation of China under Grant No.70640008, the National Social Science Foundation of China under Grant No.05BJY043 and Inner Mongolia Natural Science Foundation under Grant No.2009zd13.

\begin{abstract}
This paper presents an empirical analysis on the relationship between the size of Chinese government, as measured by its annual spending, and the growth rate of the economy. More specifically, it is designed to examine the applicability of Wagner's Law to the Chinese economy. The statistics used in this research are annual time series data on total government spending and gross domestic product covering the period of 1952 to 2007.

Unexpectedly, our empirical results showed no strong evidence in support of the validity of the Wagner's Law for Chinese economy. However, our research shows a characteristic of smooth time-varying parameters for the relationship between Chinese government expenditures and growth rate of GDP.
\end{abstract}

Keywords: Wagner's Law, Smooth time-varying parameters, Gibbs sampler, Government expenditures, GDP growth

JEL classification: C11, C14, C22, H11 


\section{Introduction}

One of the main features of the contemporary world has been the continued growth in the size of the public sector in both developing and developed countries. Researchers have developed various theories to explain the continuous increase in government expenditure; the oldest and the most cited one is the Wagner's law which suggests that during industrialization process, the share of government expenditure, both in relative and absolute terms, in total gross national product, GDP, rises as the real per capita income of a nation increases. Economists offer three key explanations for such an increase in government spending. First, the social functions of government expand through time necessitating a surge in government spending on social programs such as retirement benefits and social insurance. Second, increasing government involvement in costly investment projects, such as communication infrastructures, to support the expansion of private sector, and finally, a deeper government involvement in the economy creates a massive public debt thus increasing the costs of servicing government debts. Increasing demand for public goods and services as well as costs of dealing with the harmful externalities - the by-products of industrialization - are the other reasons for escalation of government expenditures.

Because public expenditures are considered endogenous in relation to the growth of national income, the Wagner's law has been a subject of extensive investigations. Many economic researchers have studied and empirically tested this proposition from different perspectives using different econometric methods. These studies can be roughly divided into three categories based on the econometric techniques used: The first category involves the early studies from 1960s-1990s that are considered classical and have utilized liner-based models. The traditional regression technique, Best Liner Unbiased Estimation (why capitalized?) method, is used in these studies to test the Wagner's law (Musgrave, 1969; Ram, R. 1987, Landau, Diane? anie. 1983, etc). These earlier studies did not take into consideration the time series properties of the variables examined. The empirical results of such studies have been questioned by some researchers based on methodological problems (See Chiung, 2006 for instance). The second part involves the researches after 1990s. These researches are co-integration - based studies which test for co-integration and causality between government expenditures and national income. Earlier studies of this group use the Engle and Granger methodology as main empirical analysis approach (Evkin L., 1995, Safa, 1999), whereas more recent works apply the Johansen technique. (Chang, T., 2002, Ferda, 2003.). The third part involves the researches using bounds test which is based on the unrestricted error correction model (UECM) proposed by Pesaran et al. (2001). This test procedure can be applied irrespective of whether the explanatory variables are I(0) or I(1) and to the studies with samples in small scale (Wahab, M., 2004, Chiung. 2006, Emmanuel, 2007).

However, these empirical studies have yielded mixed and sometimes contradictory results that differ considerably from country to country and period to period. These conflicting findings have been attributed to different econometric methodologies used, and to the different features charactering different economies during alternative time periods. While previous studies focus mostly on fixed coefficient which results in such mixed empirical results this paper attempts to focus on time-varying-parameter and tries to study Wagner's from a new angle. The basic idea for this is that assuming Wagner's coefficients depend on 'time' in an unknown(nonparametric) but smooth way, it can be estimated via the Gibbs sampler, by treating the unknown but smooth way as a nonparametric line to estimate the unknown parameters along with other model parameters. Here we choose China as a specified country testing the validity of the Wagner's law in China.

Choosing China as a case study has some reasons: First, China is one of the recently industrialized countries in Asia and has been made remarkable economic development over more than 20 years. Second, China has implemented an "open door" policy since the 1980s and during this period the economy system has changed from a planning economy to a market oriented economy. So the function of public finance has had some corresponding changes. Third, the relation between government expenditure and economy in China seems much complex (Wang, 2005). The ratio of government expenditure and GDP is more anther 30 percent during planning economy, 20-30 at the beginning stage of the reform, at its lowest point of 11 percent in the middle stage of 1990 s and about 25 percent after the year 2000.

The rest of the paper is organized as follows: Section 2 presents briefly a theoretical framework, whereas section Section 3 deals with the data used for the study and model set up; Section 4 presents the empirical results and the last section concludes.

\section{Modeling strategy}

Government provides public goods that can benefit an economy on the whole; household enjoy those public goods and make them in a better condition. These effects can be modeled within an endogenous growth model. If 
we assume that the representative agent has a concave continuous utility function obeying Inada conditions, then the maximization of utility function can be expressed as,

$$
\mathrm{U}=\int_{0}^{\infty}\left[\frac{\left.\mathrm{C}^{(1-\theta)}-1\right)}{(1-\theta)}\right] \mathrm{e}^{-\mathrm{pt}} \mathrm{dt}
$$

where $\mathrm{c}$ is consumption per capita and $\rho$ is discount factor. Household budget constraint relates per capita asset accumulation to the sum of the income from labor and interest income less consumption. The economy is populated with competitive producers. Each firm utilizes services financed by government expenditure in its production function.

If we further suppose that the economy is organized by two sectors (public and private); aggregate production function has the property of returning constant for scale; and the capital investments function as the proxy of the stock variable of capital accumulation, then the relationship of the government expenditure, capital input, labor input and output can be specified as,

$$
\mathrm{Y}=\mathrm{AL}^{\alpha} \mathrm{G}_{1}{ }^{\beta 1} \mathrm{G}_{2}{ }^{\beta 2}
$$

where $Y$ denotes the output level; $G_{1}$ denotes the government expenditure; $G_{2}$ denotes private capital input; $L$ is the labor input and A measures the ability of transforming

input into output. Differentiating this equation with respect to time $(\mathrm{t})$, we can obtain,

$$
\dot{y}=\frac{\dot{A}}{A}+\alpha^{*}\left(\frac{\dot{L}}{L}\right)+\beta^{*}{ }_{1}\left(\frac{\dot{G}_{1}}{G_{1}}\right)+\beta^{*}{ }_{2}\left(\frac{\dot{G_{2}}}{G_{2}}\right)
$$

This is a multifactor productivity function and the relations between (among) variables can be linearity or non-linearity. Solving equation for $g_{1}$ which equals $\frac{G_{t}}{G}$, we can get,

$$
\dot{g}_{1}=\frac{1}{\beta^{*}{ }_{1}} \dot{y}-\frac{1}{\beta^{*}{ }_{1}} \frac{\dot{A}}{A}-\frac{\alpha^{*}}{\beta^{*}{ }_{1}} \frac{\dot{L}}{L}-\frac{1}{\beta^{*}{ }_{2}} \frac{\dot{G}_{2}}{G_{2}}
$$

This is a multifactor productivity function and the relations between (among) variables can be linearity or non-linearity. From equation (4), we can obtain a simplified relation about the change of government expenditure and other related variables:

$$
\dot{g}_{1}=\alpha+\beta \dot{y}
$$

Equation (6) provides a simple framework for estimating Wagner's relationship. In practice, it is common to allow for some short-run dynamics when time series data are used. Based on this idea the model can be written as,

$$
\dot{g}_{1}=\alpha_{0}(t)+\sum_{j=1}^{p} \alpha_{j}(t) \dot{g}_{j-1}+\beta(t) y_{t}+\varepsilon_{t}
$$

Where $\mathrm{t}=\mathrm{p}+1, \mathrm{p}+2, \ldots, \mathrm{T}$ and the optimal lag length $\mathrm{p}$ can be determined by the one minimizing Akaike's Information Criterion (AIC) or Bayesian Information Criterion (BIC). Here the intercept $\alpha(t)$, the autoregressive coefficients $\alpha(t)_{j} j=1,2, \ldots, p$, and the Wagner's coefficients $\beta(t)$ are all allowed to change over time. Moreover they are entirely characterized by distinct unknown but smooth function of time. Although the functional forms of $\alpha(\mathrm{t})$ and $\beta(\mathrm{t})$ are unknown and remain unspecified, they can be estimated non-parametrically by the simulation-based Bayesian approach.

This equation can be further expressed in a more compact way,

$$
y=X \gamma+\varepsilon
$$

Where $X=\left(X_{0}: X_{1}: \ldots . . X_{p+1}\right) \quad \gamma=\left(\gamma_{0}^{\prime}, \gamma_{1}^{\prime}, \ldots . \gamma_{p+1}^{\prime}\right)^{\prime}, y=\left(\stackrel{\bullet}{\bullet} \cdot \stackrel{\bullet}{g_{1, p+1}, g_{1, p+2}, \ldots . . g_{1, T}}\right), \quad X_{0}$ is a $n \times n$ identity matrix (here $\left.\mathrm{n}_{\bullet} \mathrm{T}-\mathrm{p}\right), X_{j}$ is a $n \times n$ diagonal matrix with diagonal elements given by $\left(g_{1, p+1-j}, g_{1, p+2-j}, \ldots . . g_{1, T-j}\right)$, and with corresponding coefficients $\gamma_{j}=\left[\alpha_{j}(1), \alpha_{j}(2), \ldots \ldots \alpha_{j}(n)\right], j_{\bullet}=0,1, \ldots, p, \quad X_{p+1}$ is also a $n \times n$ diagonal matrix with diagonal elements given by $\left(y_{p+1}, y_{p+2} \ldots y_{T}\right)^{\prime}$, with corresponding time-varying Wagner's 
coefficients $\gamma_{p+1}=[\beta(1), \beta(2), \ldots \ldots \beta(n)]^{\prime} \quad \varepsilon=\left(\varepsilon_{p+1}, \varepsilon_{p+2}, \ldots, \varepsilon_{T}\right)^{\prime}: N\left(0, \sigma^{2} I_{n}\right)$

Our main task is to estimate $\left(\gamma_{0} \gamma_{1}, \ldots, \gamma_{\mathrm{p}}, \gamma_{\mathrm{p}+1}, \sigma^{2}\right)$.

\section{Data description and model}

The data under examination consist of gross domestic products (GDP) and total government expenditure (CZ) for the period of 1952-2007. Both were deflated by constant price of 1990. The data were obtained from the China Statistical Yearbook and were specified in logarithmic form. We took 1952 as the starting point because this is the earliest formal data we can get for the P.R China. What we must indicate is that Chinese Government revenue system is slightly complex with five level funds collecting and distributing system. The funds were managed in two categories, the tax and non tax revenues which are about $70 \%$ and $30 \%$ respectively. Accordingly, the government's expenditure system also can be divided into government budgetary spending and government non tax budgetary spending. The former can be categorized into government consumption expenditure and investments in infrastructure; the latter is divided into expenditures of special funding. In the present paper, we use tax based expenditure as a proxy of government size.

Figure 1 shows there is common tendency between GDP and government expenditure. From 1952 to 1995, there are three increasing stages and four decreasing stages for both of these two variables. The three increasing stages are 1951-1954, 1956 - 1957, 1959 - 1992. The amplitudes of these three increasing stages are $11.61 \%, 2.01 \%$, $19.91 \%$ and average amplitude is $11.18 \%$. The four decreasing stages are 1978-1981, 1984-1986, 1987-1989, 1992-1995. The amplitudes of these four stages are $4.80 \%, 10.19 \%, 13.18 \%, 7.99 \%$ respectively and average amplitude is $9.04 \%$. So, on the whole, there are four pro-cyclical and these pro-cyclical characteristic of some great variation, which means some problems exist. After 1996, The amplitude of Chinese economy represents a Fat-tail stationary and the difference between Peak bit and lowest bit of the increase rate of GDP is only 2.1 percent; average amplitude is $0.42 \%$. For the ratio of government expenditure to GDP (see figure 2), the situation is slightly different. The ratio of Chinese government expenditure to GDP shows a very significant time varying feature. It had great amplitude for the whole sample space

Figure 1

Figure 2

Because most of the time series are not stable, we used ADF method to test the unit root. The test results show that the logarithm of the two time series were not stable. However, they were stable after taking one lagged difference. This indicates that these variables in logarithm belong to integration one process (I(1)) (see Table 1)

Table 1

To support Wagner's law, a unidirectional from GDP to government expenditure is required. So we use Granger causality test to further study the relationship between government expenditure and GDP in China. In the test, causality is hypothesized to run from GDP to the dependent variable. In other words, the hypothesis that GDP causes government expenditure requires that government expenditure does not cause GDP. The test carried out using the first differences of each series (DLnCZ, DLnGDP). The null hypothesis of non causality is tested using F-statistics. The results are presented in table 2. They show that there is a feedback effect (or bilateral) and no clear evidence to support the validity of Wagner' law in China.

Table 2

\section{Empirical results}

\subsection{Fixed-parameters analysis}

For comparison reason, we first estimate the linear regression. Although not explicitly specified, all the priors are set to be relatively diffuse. In doing so, we can avoid the estimation results to be dominated by the subjective priors but to reflect mainly the information from (objective) data. cording to AIC criterion, the optimal lagged is 1 .

The fixed parameters regression:

$\mathrm{DLnCZ}_{\mathrm{t}}=-0.038207+0.0837 \mathrm{DLnCZ}_{\mathrm{t}-1}+1.2344 \mathrm{DLnGDP}_{\mathrm{t}}$

\begin{tabular}{|c|c|c|}
\hline $\mathrm{T}$ value & 0.8242 & 6.7582 \\
\hline$P$ value & 0.4138 & 0.0000 \\
\hline$\sigma^{2}=0.01496$ & $\mathrm{R}^{2}=0.5150 \quad \mathrm{DW}=1.5986$ & $\mathrm{LM} \mathrm{X}^{2}(2) \mathrm{P}-$ value $=0.0456$ \\
\hline
\end{tabular}


RESET F $(1,49) \mathrm{P}$-value $=0.00$

The year 1979, CHOW F $(3,47) \mathrm{P}$-value $=0.0000$

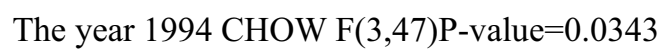

(The point of CHOW test is 1979 and 1994)

According to the results of the regression, the elasticity of GDP with respect to government expenditure is 1.2344 , it means that government expenditure will increase about 1.2344 units with GDP's increasing one unit on average. This result supports Wagner's hypothesis. But the tests of WHITE, RESET and CHOW show that there are some problems in model specification, so we should do some further analysis on the relationship between these two variables.

\subsection{Smooth-time-varying results}

Based on what discussed above, the tradeoff between (differenced) government expenditure and output might vary over time, suggesting that Wagner's coefficients can be time-varying. To allow for this possibility, we estimate the parameters with smooth time varying (STV) parameters by the Gibbs sampling algorithm. Here the initial values are $\mathrm{v}_{0,0}=\delta_{0,0}=\mathrm{v}_{1,0}=\delta_{1,0}=\mathrm{v}_{2,0}=\delta_{2,0}=\mathrm{v}_{0}=\delta_{0}=10^{-3}$, the Markov chain Monte Carlo algorithm is run for 20, 000 iterations. The first 10,000 draws were discarded in order to mitigate the effect of initial values and to assure the convergence of the chain. The last 10,000 sample variants are collected and used for making posterior inference of the relevant parameters. The results are summarized in Table 3 and Figure 3.

Table 3

Figure 3

In Table 3, we first find that the mean value of the variance term $\sigma^{2}$ is calculated to be 0.0045 . It is smaller than that obtained from the linear regression model (which is 0.0149). Obviously, the simulation effect of the time varying model is much better. Other estimated coefficients also show expected features and $\eta_{0}, \eta_{1}$ and $\eta_{2}$ are significant at $95 \%$ Bayesian confidence intervals. Note that all of these smoothing parameters are very small which imply the estimates of $\gamma_{0}, \gamma_{1}$ and $\gamma_{2}$ will be very smooth. This conjecture is confirmed by looking at Figure 3 , where the time varying constant terms (top panel), autoregressive parameters (middle panel), and Wagner's coefficients (bottom panel), each measured by their respective estimated mean values, are plotted against time.

From the top panel of Figure 3, we can see that the constant term $\alpha_{0}(t)$ shows a very clear $U$ shape form over the whole period. This can be taken as evidence in justifying our time varying-constant setup rather than the commonly-used fixed intercept assumption. Additionally, the middle panel of Figure 3 also indicates that the first order autoregressive parameters display large variations, i.e., the dynamics of the government expenditure rates change a lot across the sample period. More importantly, the bottom panel of Figure 3 provides the mean estimates for the government expenditure and GDP trade-off, which is so called Wagner's coefficients, from 1952 to 2007. As argued in many previous studies, the tradeoff between government expenditure growth and GDP growth might change over time. According to the figure, those estimates clearly show a stage feature of the relationship between government expenditure and GDP. The elasticity of GDP with respect to government expenditure is larger than one during the period of 1952 to 1990, during which China economy was a planned economy and smaller after 1990, during which China economy was a marketing oriented economy. Although this test has not yielded results that support Wagner's law in China, it did reveal a very important feature of the Chinese finance system. That is, the function of the Chinese finance system under planning oriented economic system was quite limited because government expenditures were endogenously existed. After 1990, especially after the establishment of a new tax system, this situation has changed a great deal; the function of the public finance has been strengthened and the fiscal policy plays a more important role in economic adjustment. This phenomenon may also be attributed to government expending their expenditure during recession periods and decreasing their spending during booming periods. Meanwhile, capacity utilization is changed, falling during recessions and rising during expansions. Labor demand is also changing, increase during booming and decreases during recessions. With government expenditure, hours per worker, capital utilization, and productivity varying with output growth.

\section{Conclusions}

In the light of the reported empirical results in this paper, we get following two basic concludes: Firstly, the overwhelming evidence of time varying Wagner's relationship between China's GDP and government expenditure indicates that the conventional fixed parameters specification can lead to inappropriate, if not incorrect results. 1, In case of China, smooth time varying (STV) parameters approach may be a suitable choice 
for estimating Wagner's law. Secondly, although this test has not yielded results that support the validity of Wagner's law in China, they did reveal a very important fact. That is the function of Chinese finance system under planning oriented economic system was quite limited because of government expenditure endogenously existed in the planning economy system; the function of the public finance under marketing oriented economy has been strengthened because of government expenditure exogenously existed in the reform oriented economy system. 2, This time-varying feature of Wagner's law's coefficient may reflect the fact that the movements in government institutions and size change the responses of multifactor productivity. During industrialization, the administrative and regulatory functions of the state would substitute public for private activity; economic growth would lead to an increase in cultural and welfare services, which are assumed to be income elastic; and state participation would be required to provide the capital funds to finance large-scale projects made to satisfy the technological needs of an industrialized society, not met by the private sector. On the other side, government spending may also rise disproportionately with growth as a result of the utility maximizing behavior of the bureaucrats (Niskanen, 1971); public choice motivations (Persson and Tabellini, 1990): and the role of interest groups being able to capture government through the majority rule, etc.

\section{References}

Chang, T. (2002). An econometric test of Wagner's law for Six Countries based on cointegration and error-correction modeling techniques. Applied economics, 34, 1157-69.

Chiung-Juhuang. (2006). Government expenditure in China and Taiwan: do they follow Wagner's law?. Journal of economic development, 139 vol. 31, No. 2, December , pp139-148.

Emmanuel Ziramba. (2007). Wagner's law: A economic test for south Africa, 1960-2006. South Africa journal of economics, vol. 76, No.6, pp 596-606.

Evkin L. Bairam. (1995). Level of aggregation, variable elasticity and Wagner's law. Economics letters, vol.48, Issues 3-4, June 1995, pp341-344.

Ferda Haliciolu. (20030. Testing Wagner's law for Turkey, 1960-2000, Review of middle east conomics and finance. Taylor and francis journals, August, vol. 1(2), pp 129-140.

H.-C. Huang and S.-C. Lin. (2008). Smooth-time-varying Okun's coefficients. Economic Modelling, 25, pp363-375.

Landau, Danie. (1983). Government expenditure and economic growth, a cross-country study. Southen economic journal, 49 Jan: pp783-790.

Musgrave, R.A. (1969). Fiscal System. New Haven: Yale University Press.

Niskanen, W.A. (1971). Bureaucracy and Representative Government. Aldine-Atherton, Chicago.

Persson, T., and G. Tabellini. (1990). Macroeconomic Policy, Credibility and Politics. Harwood Academic, London.

Pesaran, H., Shin, Y., and R.J. Smith. (2001). Bounds testing approaches to the analysis of level relationships. Journal of applied econometrics, 16, pp289-326.

Ram, R. (1987). Wagner's hypothesis in time-series and cross-section perspectives. Public finance, 41 (3): pp393-414.

Safa Demirbas. (1999). Cointegration analysis-causality testing and Wagner's law: The case of Turkey, 1950-1990, Working paper.

Wahab, M. (2004). Economic growth and government expenditure: evidence from a new test specification. Applied economics, 36, 2125-35.

Wang Xiao-Li. (2005). An Analysis on the Basic Characteristics of Chinese Government Non-tax Revenue System. Journal of Central University of Finance and Economics. 2005(03). (Reprinted by Review of Economic Research, 2005(47)) 
Table 1. Unit root test (ADF)

\begin{tabular}{|l|l|l|l|l|}
\hline \multirow{2}{*}{ Yariable } & \multicolumn{2}{|l|}{ level } & \multicolumn{2}{l|}{ difference } \\
\cline { 2 - 5 } & ADF & test & ADF & test \\
\hline LnCZ & -0.4068 & $(\mathrm{C}, \mathrm{T}, 2)$ & $-6.3178^{* *}$ & $(\mathrm{C}, 0,1)$ \\
\hline LnGDP & -1.1829 & $(\mathrm{C}, \mathrm{T}, 2)$ & $-4.0985^{* *}$ & $(\mathrm{C}, 0,1)$ \\
\hline
\end{tabular}

Note:* represents $5 \%, * *$ represents $1 \%$

Table 2. The results of Granger causality test

\begin{tabular}{|l|l|l|l|}
\hline Null hypothesis: & F Values & P Values & conclusion \\
\hline DLnCZ does not cause DLnGDP & 2.7095 & 0.07697 & $10 \%$ statistical significant \\
\hline DLnGDPdoes not cuse DLnCZ & 4.6899 & 0.01390 & $5 \%$ statistical significant \\
\hline
\end{tabular}

Note: 2 lag(AIC)

Table 3. The results of the STV model

\begin{tabular}{|l|l|l|l|l|l|l|l|}
\hline & mean & std & median & $2.5 \%$ & $5 \%$ & $95 \%$ & $97.5 \%$ \\
\hline$\eta_{0}$ & 0.021 & 0.0043 & 0.0204 & 0.0142 & 0.015 & 0.0288 & 0.0307 \\
\hline$\eta_{1}$ & 0.0238 & 0.0048 & 0.0232 & 0.0161 & 0.017 & 0.0325 & 0.0349 \\
\hline$\eta_{2}$ & 0.0283 & 0.0059 & 0.0275 & 0.019 & 0.0201 & 0.0391 & 0.0420 \\
\hline$\sigma^{2}$ & 0.0045 & 0.0020 & 0.0042 & 0.0017 & 0.0020 & 0.0082 & 0.0093 \\
\hline
\end{tabular}

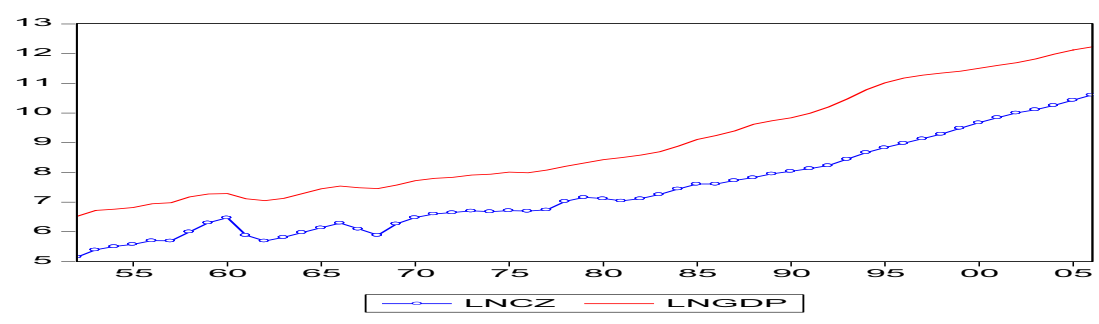

Figure 1. The time series plots of the real GDP (LnGDP, the red solid line) and government expenditure (LnCZ, blue doted line) from 1952 2006 respectively.

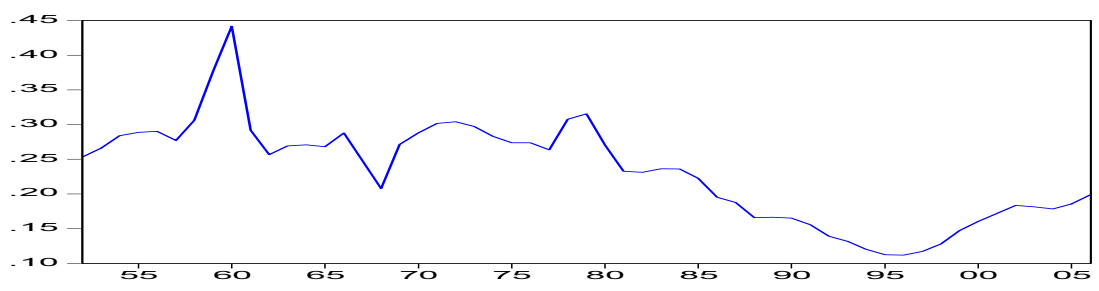

Figure 2. The ratio of government expenditure to GDP 

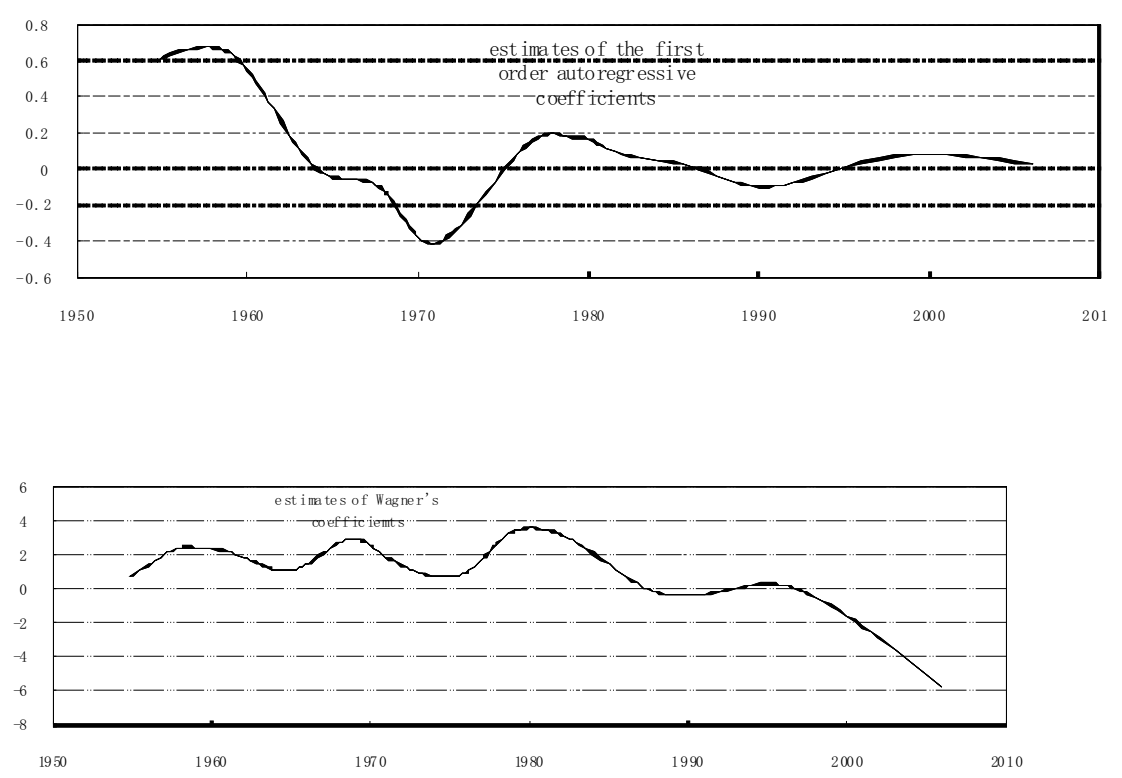

Figure 3. The time series plots of mean estimated values of constants (top panel), autoregressive parameters (middle panel), and Wagner's coefficients (bottom panel) 